\title{
Distribution of Brugia malayi larvae and DNA in vector and non-vector mosquitoes: implications for molecular diagnostics Sara M Erickson ${ }^{1}$, Kerstin Fischer ${ }^{2}$, Gary J Weil ${ }^{2}$, Bruce M Christensen ${ }^{1}$ and Peter U Fischer*2
}

Address: ${ }^{1}$ Department of Pathobiological Sciences, University of Wisconsin-Madison, Madison, Wisconsin, USA and ${ }^{2}$ Department of Internal Medicine, Infectious Diseases Division, Washington University School of Medicine, St Louis, Missouri, USA

Email: Sara M Erickson - smerickson@wisc.edu; Kerstin Fischer - kerstinfischer@sbcglobal.net; Gary J Weil - gweil@DOM.wustl.edu; Bruce M Christensen - Christensen@svm.vetmed.wisc.edu; Peter U Fischer* - Pufische@DOM.wustl.edu

* Corresponding author

Published: 17 November 2009

Parasites \& Vectors 2009, 2:56

(c) 2009 Erickson et al; licensee BioMed Central Ltd.

This is an Open Access article distributed under the terms of the Creative Commons Attribution License (http://creativecommons.org/licenses/by/2.0), which permits unrestricted use, distribution, and reproduction in any medium, provided the original work is properly cited.

\begin{abstract}
Background: The purpose of this study was to extend prior studies of molecular detection of Brugia malayi DNA in vector (Aedes aegypti- Liverpool) and non-vector (Culex pipiens) mosquitoes at different times after ingestion of infected blood.

Results: Parasite DNA was detected over a two week time course in $96 \%$ of pooled thoraces of vector mosquitoes. In contrast, parasite DNA was detected in only $24 \%$ of thorax pools from nonvectors; parasite DNA was detected in $56 \%$ of midgut pools and $47 \%$ of abdomen pools from nonvectors. Parasite DNA was detected in vectors in the head immediately after the blood meal and after 14 days. Parasite DNA was also detected in feces and excreta of the vector and non-vector mosquitoes which could potentially confound results obtained with field samples. However, cohousing experiments failed to demonstrate transfer of parasite DNA from infected to non-infected mosquitoes. Parasites were also visualized in mosquito tissues by immunohistololgy using an antibody to the recombinant filarial antigen $\mathrm{Bm} \mathrm{I4}$. Parasite larvae were detected consistently after $\mathrm{mf}$ ingestion in Ae. aegypti- Liverpool. Infectious L3s were seen in the head, thorax and abdomen of vector mosquitoes I 4 days after Mf ingestion. In contrast, parasites were only detected by histology shortly after the blood meal in $C x$. pipiens, and these were not labeled by the antibody.

Conclusion: This study provides new information on the distribution of filarial parasites and parasite DNA in vector and non-vector mosquitoes. This information should be useful for those involved in designing and interpreting molecular xenomonitoring studies.
\end{abstract}

\section{Background}

Human lymphatic filiarasis (LF) is caused by the mosquito-borne filarial nematodes Wuchereria bancrofti, Brugia malayi, and B. timori. These parasites are currently targeted for elimination by the Global Program for the Elimination of Lymphatic Filariasis (GPELF), and workers in this program have reported both achievements and future challenges to eliminating parasite transmission in endemic areas [1-3]. One important component of the elimination program is the ability to estimate infection prevalence and transmission rates, especially during mass drug administration (MDA), in order to accurately evalu- 
ate the progress towards the goal of LF transmission interruption [4]. Molecular detection assays provide sensitive and specific tools for identifying and distinguishing parasites in host populations. Molecular techniques commonly used to study LF infection, or exposure, in humans include the detection of parasite DNA, circulating filarial antigen, and filarial antibodies in blood samples [5]. Molecular techniques also have been applied to the detection of filarial worms in mosquitoes, and these primarily target parasite DNA [6-9].

The detection of parasite DNA in mosquito samples is a valuable tool for molecular xenomonitoring (MX), but this does not differentiate parasite developmental stages or distinguish whether the DNA is from living or dead parasites [10-12]. Recently, RNA-based assays have been developed to detect $B$. malayi and $W$. bancrofti in mosquitoes $[13,14]$, including the distinction of $B$. malayi infected (a constitutive parasite transcript) and infective mosquitoes (a L3-specific transcript) [14]. However, RNAbased detection assays have not yet been tested in the field or incorporated into LF surveillance programs. Vector-parasite interactions influence the applicability and interpretation of molecular detection assays used in vector surveillance studies. There are several factors that should be carefully considered when using molecular techniques to investigate parasites within the mosquito intermediate host, including the (1) various life cycle stages and their tissue locations, (2) likelihood of parasite development to the infective stage, i.e., vector competence, and (3) limitations of the particular detection assay, i.e., ability to distinguish infection stages and living from dead parasites. The separation of mosquitoes into body regions has been used to circumvent the inability of some assays to distinguish infective-stage parasites. For example, Anopheles spp. have been divided into two body regions (head/thorax and abdomen) to provide better estimates of mosquitoes infected with Plasmodium sporozoites and/or pre-sporo- zoite stages [15-17] and the heads of blackflies have been removed (by mass dissection techniques) for the restricted, head-only, PCR assays targeting Onchocerca DNA, which is more likely to provide a better estimate of infective-stage parasites because other developmental stages generally reside outside of the head $[18,19]$.

The studies conducted herein follow our previous work, which demonstrated that DNA-based diagnostics are unable to distinguish the developmental stage of LF parasites or whether parasites are living or dead in the mosquito [10]. Despite these limitations, there are benefits to using DNA-based assays over dissection to assess the persistence of filariasis in populations. Because filarial DNA is detectible for two weeks or longer following a microfilaremic blood meal in both vector and non-vector mosquitoes, all anthropophilic mosquitoes can be included in the screening of mosquitoes for parasite DNA to provide MX data [10]. Herein, we have further examined the persistence of filarial parasites and parasite DNA in mosquitoes; we used a combination of mosquito dissection, immunohistology and PCR assays to determine the location(s) of filarial worms and DNA in mosquitoes that are susceptible or refractory to filarial parasite development. These studies allowed us to assess the potential value of tissue specific assays (e.g., mosquito heads only) to estimate the prevalence of infective-stage larvae in mosquitoes; we also investigated the issue of direct mosquito to mosquito transfer of parasite DNA that could confound MX studies.

\section{Results}

Development of B. malayi in Ae. aegypti and Cx. pipiens Table 1 summarizes the recovery of parasites from dissected mosquitoes. In Ae. aegypti-LVP, 73.6\% of the recovered B. malayi $\mathrm{mf}$ at $2 \mathrm{~h}$ post ingestion (PI) had successfully penetrated the midgut, with $49.4 \%$ located in the thorax. At 14 days post ingestion of microfilaremic blood (DPI), 80\% of Ae. aegypti harbored L3s. In contrast,

Table I: Distribution of B. malayi larvae in vector and non-vector mosquitoes as assessed by dissection.

\begin{tabular}{|c|c|c|c|c|c|c|c|}
\hline & \multirow[t]{2}{*}{ Time post ingestion } & \multicolumn{4}{|c|}{ Number of parasites recovered ${ }^{a}$} & \multirow[t]{2}{*}{ Total worms ${ }^{a}$} & \multirow{2}{*}{$\begin{array}{c}\text { Percentage of mosquitoes harboring } \\
\text { parasites }\end{array}$} \\
\hline & & Midgut & Abdomen & Thorax & Head & & \\
\hline \multirow{3}{*}{ Ae. aegypti-LVP } & $2 \mathrm{~h}$ & 23 & 21 & 43 & n.d. & 87 & $93 \%(6.2 \pm 6.1)^{b}$ \\
\hline & $7 \mathrm{~d}$ & 0 & 0 & 65 & 0 & 65 & $73 \%(5.9 \pm 5.9)$ \\
\hline & $14 d$ & n.d. & 7 & 30 & 22 & $59(20)$ & $80 \%(3.9 \pm 3.2)$ \\
\hline \multirow[t]{3}{*}{ Cx. pipiens } & $2 \mathrm{~h}$ & 100 & 4 & 0 & n.d. & 104 & $93 \%(7.5 \pm 7.1)$ \\
\hline & $7 d$ & 0 & 4 & 0 & 0 & 4 & $13 \%(2.0 \pm 1.4)$ \\
\hline & $14 \mathrm{~d}$ & $0(10)$ & 0 & 0 & 0 & 0 & $0 \%$ \\
\hline
\end{tabular}

aParasites were observed in mosquito dissections by microscopy at various times after ingestion of microfilaremic blood. Fifteen mosquitoes were dissected at each time point, except as noted (n.d., 10, or 20).

bMosquito infection rate (mean intensity \pm SD) 
from $C x$. pipiens only $\mathrm{mf}$ were recovered and $93 \%$ of them were found in the midgut lumen.

B. malayi DNA detection in pooled mosquito body regions PCR results are summarized in Figure 1. Parasite DNA was detected in $74 \%$ of $A e$. aegypti-LVP pooled body region samples $(n=300)$ and $36 \%$ of $C x$. pipiens $(n=300)$ pooled body regions tested. These differences were highly significant $(P<0.0001)$. In Ae. aegypti-LVP, parasite DNA was detected in all four body regions with $43,71,88$, and $96 \%$ of heads, midguts, abdomens, and thoraces $(n=75$ for each) positive by $\mathrm{qPCR}$, respectively. Parasite DNA also was detected in all $C x$. pipiens body regions, with 17 , 24,47 , and $56 \%$ of heads, thoraces, abdomens, and midguts ( $\mathrm{n}=75$ for each) positive, respectively. The differences in the percentage of $B$. malayi DNA positive samples were significant between mosquito species in all body regions (heads, $P=0.001$; thoraces, $P<0.0001$; abdomens, $P<0.0001)$ except the midguts $(P=0.09)$. The detection of parasite DNA within certain mosquito body

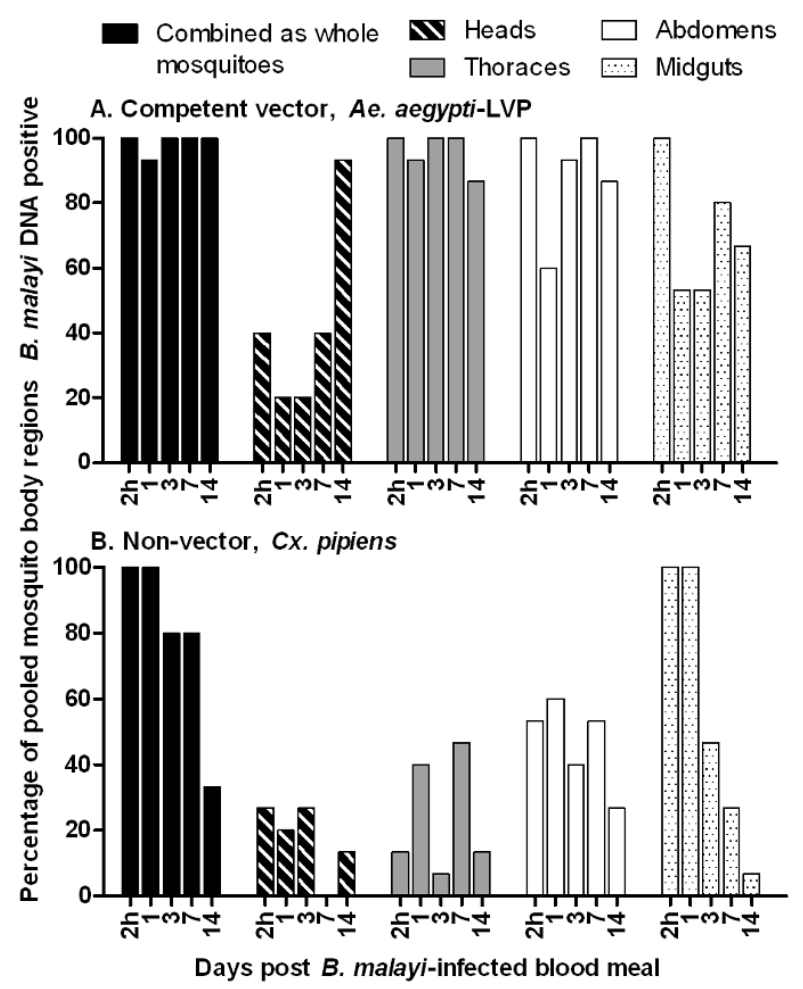

Figure I

Prevalence of B. malayi DNA in pooled samples of experimentally infected mosquitoes by body part (head, thorax, abdomen, and midgut) at different times post ingestion of microfilaremic blood. A Ae. aegypti-LVP, competent $B$. malayi vector $\mathbf{B} C x$. pipiens, $B$. malayi non-vector. regions was positively or negatively correlated with time. Specifically, the detection of $B$. malayi DNA was negatively correlated with time in 'whole body' $C x$. pipiens $\left(\mathrm{r}^{2}=0.93\right.$, $P=0.0075)$ and $C x$. pipiens midguts $\left(r^{2}=0.82, P=0.034\right)$, and positively correlated with time in Ae. aegypti-LVP heads $\left(\mathrm{r}^{2}=0.77, P=0.05\right)$.

\section{B. malayi DNA detection in individual mosquito body regions}

Individual mosquitoes that were separated into body regions for DNA detection assays were compared to results of the pooled mosquito body regions (Fig. 2). Following a microfilaremic blood meal of $191 \mathrm{mf} / 20 \mu \mathrm{l}$ blood, there was no difference in DNA detection between pooled and individual Ae. aegypti-LVP body regions $(P$ values $=0.35-0.61)$ or between pooled and individual $C x$. pipiens body regions $(P$-values $=0.78-1.0)$.

\section{Detection of parasite DNA in mosquito excreta and feces} Figure 3 summarizes the detection of $B$. malayi DNA in individual housed mosquitoes and their voided excreta and feces. All mosquitoes were positive for parasite DNA immediately ( $2 \mathrm{hr}$ ) after ingesting microfilaremic blood. From 1-4 DPI all Ae. aegypti-LVP tested positive for parasite DNA, and three of these (15\%) mosquitoes had detectible B. malayi DNA in their feces. In contrast, $60 \%$ of $C x$. pipiens were DNA negative at 4 DPI, but $B$. malayi DNA was detected in $100 \%$ of $C x$. pipiens feces tested at 3-4 DPI. Of the twenty samples of feces collected over the entire observation period of 1-4 DPI from each species, $B$. malayi DNA was detected in 15 and 65\% of Ae. aegypti-LVP and $C x$. pipiens fecal samples, respectively $(P=0.003)$.

\section{Parasite DNA contamination of B. malayi positive and negative mosquitoes}

In order to test the possibility that infected mosquitoes contaminate uninfected mosquitoes while they are together in the same trap or sampling tube, we housed uninfected $A e$. aegypti-LVP together with $C x$. pipiens that had fed on a microfilaremic gerbil. After 7 days, mosquitoes were collected and pooled by species. None of the 17 Ae. aegypti-LVP pools (with 10 mosquitoes per pool) were positive by real-time PCR. In contrast, 17 of the $21 \mathrm{Cx}$. pipiens pools (with 5 mosquitoes each) were positive. Most of these samples had relatively high $\mathrm{Ct}$ values indicating small amounts of B. malayi DNA, but 5 pools had higher Ct values ranging between 29 and 35. Although B. malayi DNA can be detected in feces of infected mosquitoes, feces did not cause false positive DNA signals from uninfected mosquitoes after co-housing.

\section{Detection of Bm I4 in mosquito-stage parasites by immunohistology}

Immunohistology studies were performed to confirm the dissection results and to better document the fate of $B$. 


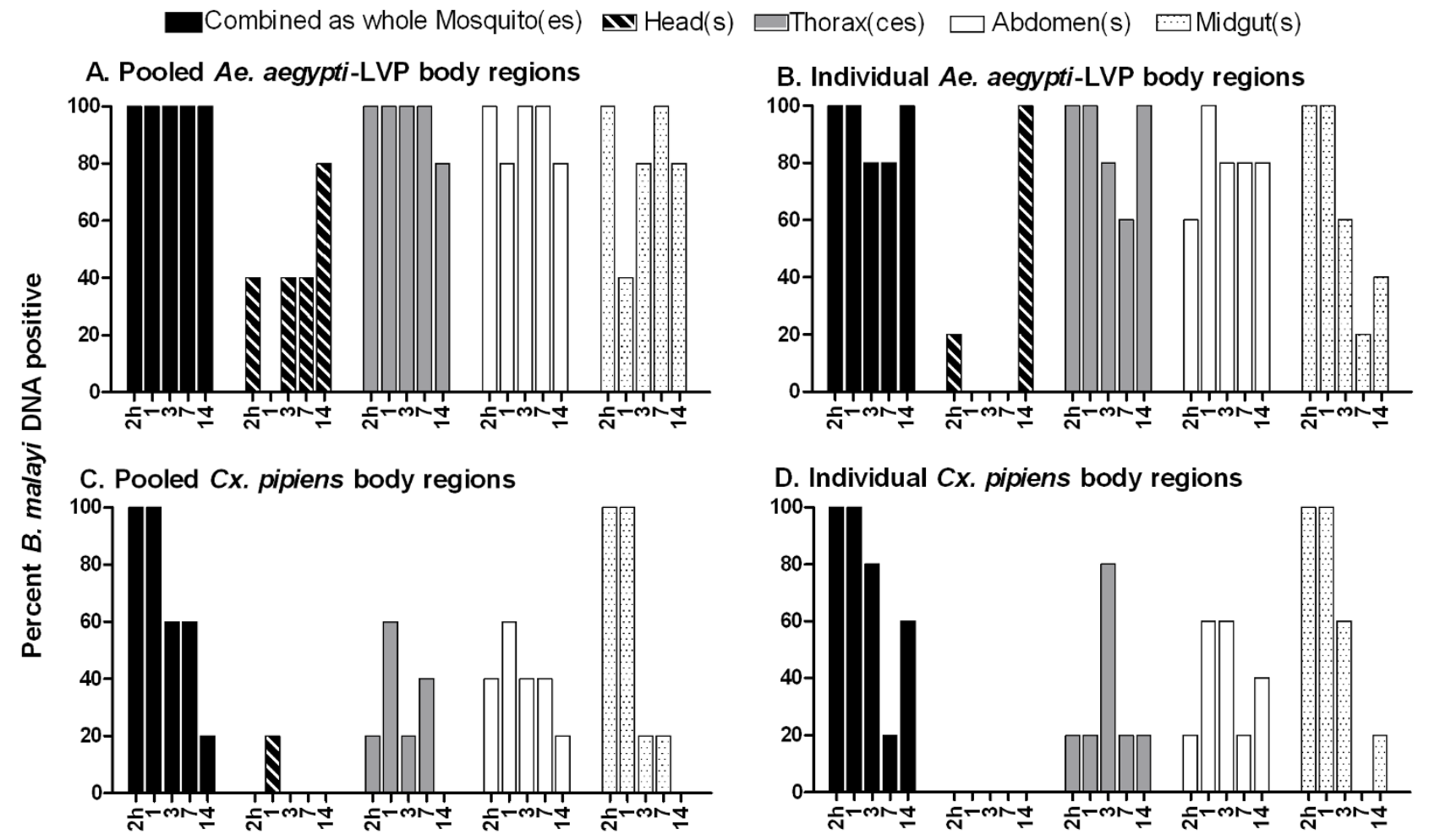

Days post B. malayi-infected blood meal

Figure 2

Comparison of B. malayi DNA prevalence in pooled and individually tested mosquito body parts. A Ae. aegyptiLVP body parts were tested in pools of four. B Ae. aegypti-LVP body parts individually tested for parasite DNA. C Cx. pipiens body parts tested in pools of four. D Cx. pipiens body parts individually tested for B. malayi DNA.

malayi in vector and non-vector mosquitoes. In Ae. aegyptiLVP, unlabeled $\mathrm{mf}$ were detected within the midgut directly after the bloodmeal (Fig. 4A). Strong-labeling was observed with the Bm14 antibody after the larvae reached the thoracic muscles. Thus this antibody can be used to sensitively detect developing filarial larvae in vectors (Fig. 4B-E). Strongly labeled L3s were observed in all body parts of Ae. aegypti-LVP at 14 DPI (Fig. 4F-G). L3s were not confined to the head or the thoracic musculature; they were also seen in the abdomen, outside of the midgut (Fig. 4J).

Stretched, intrauterine $\mathrm{mf}$ in adult female $B$. malayi are usually labeled by the Bm14 antibody (Fig. 5A), but mf were not labeled in the midgut of $C x$. pipiens directly after the blood meal. No larvae were detected in histological sections of $C x$. pipiens at later times points (Fig. 5C, D). Dead and/or dying larvae in the thorax of Brugia refractory Ae. aegypti-RKF were not labeled by Bm14 (Fig. 5G, I, J). In contrast, developing larvae in Ae. aegypti-LVP were always strongly labeled at the same time points (Fig. 5F, H).
These results suggest that the anti-Bm14 antibody specifically detects viable and developing $B$. malayi larvae in vectors.

\section{Discussion}

The application of molecular assays to detect parasites within vectors is influenced by the vector-parasite interaction. In these studies, we analyzed the detection of filarial worms in susceptible and refractory mosquitoes by targeting parasite DNA or protein in molecular assays. The three mosquito strains examined have very different interactions with B. malayi that were documented in our previous paper on detection of parasite DNA from living and dead parasites within mosquitoes [10]. The follow-up studies discussed herein were designed to investigate: (1) the mosquito body region(s) containing the persistently detected parasite DNA within $C x$. pipiens (in this mosquito species $\mathrm{mf}$ are seldom able to migrate out of the midgut lumen), and (2) the detection of parasite proteins as larvae develop in susceptible and refractory mosquitoes. 


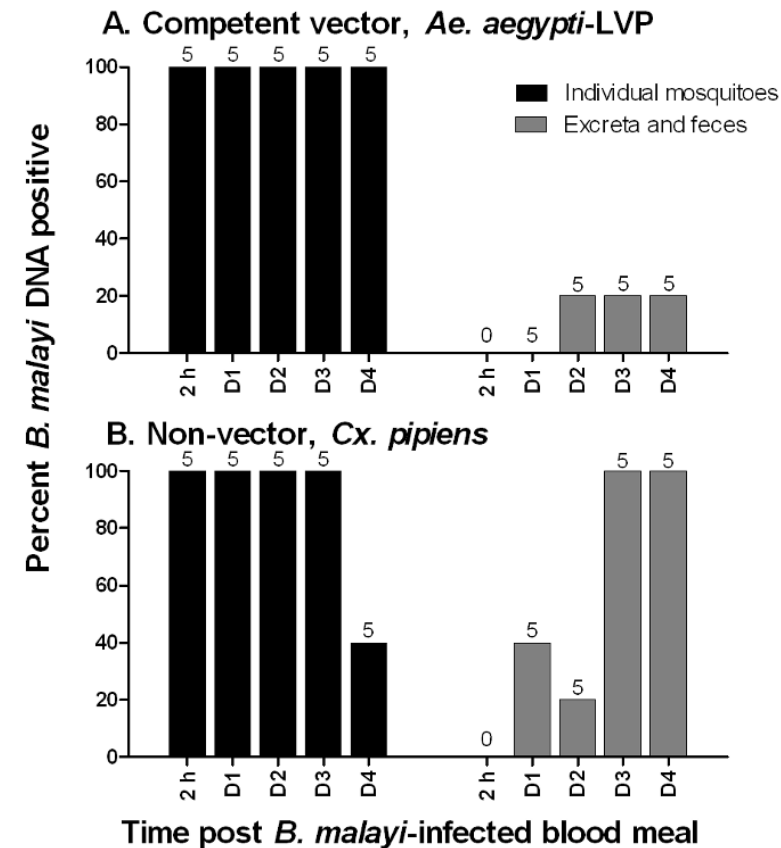

Figure 3

Detection of B. malayi DNA in mosquito feces. A

Prevalence of parasite DNA in individually housed Ae. aegyptiLVP and their feces. B Prevalence of parasite DNA in individually housed $C x$. pipiens and their feces. Sample number is indicated above each bar.

Separation of mosquitoes into body regions (head, thorax, abdomen, and midgut) prior to PCR assays provided further details on the location of detectible parasite DNA within mosquitoes. In both vector Ae. aegypti-LVP and non-vector $C x$. pipiens, the head region had the lowest parasite DNA detection rates (43 and 17\% respectively) when all time points are considered. However, there was a striking difference at 14 days when nearly $100 \%$ of pools of Ae. aegypti-LVP heads and very few pools of $C x$. pipiens heads contained parasite DNA. This finding correlates well with infectivity rates at that time point. Although DNA detection in mosquito heads might provide a better estimate of infectivity rates than DNA detection in whole mosquitoes (Fig. 2), we do not advocate separating heads for this purpose in field studies, because false positive and false negative infectivity signals are likely to be high with this approach. Because PCR can detect DNA from live or dead parasites from any developmental stage, heads could be falsely positive (without L3s being present) because of remnants of ingested $\mathrm{mf}$ (especially in mosquitoes with armed cibarial and/or pharyngeal pumps). Heads could provide a false negative infectivity signal when mosquitoes contain L3s in other body parts. Our results and prior studies [20] have shown that L3s are not restricted to the head.
B. malayi DNA also was not restricted to the midgut in $C x$. pipiens. Although most $\mathrm{mf}$ do not leave the Cx. pipiens midgut lumen, $\mathrm{mf}$ are sometimes detected outside of the midgut by dissection (Table 1 and Erickson and Christensen, unpublished data). Although these few $\mathrm{mf}$ that do penetrate the midgut epithelium could be the source of parasite DNA outside of the Cx. pipiens midgut, an alternative explanation was also examined. In compatible vectors, the majority of $\mathrm{mf}$ penetrate the midgut epithelium very quickly (within $1.5 \mathrm{~h}$ ) after ingestion [21], and those that are unable to penetrate remain within the midgut lumen and are destined for digestion and/or defecation. This is in agreement with our observation that at $2 \mathrm{~h}$ PI almost $50 \%$ of $\mathrm{mf}$ were recovered from the thorax. In parasite-vector pairs that limit or prevent mf penetration of the mosquito midgut (e.g., Brugia--Cx. pipiens and certain Wuchereria--Culex spp. interactions) [22-25], parasite material is likely to be shed in mosquito feces. To test the hypothesis that DNA detected outside of the midgut is due to parasite DNA on exterior mosquito surfaces, excreta and feces from Ae. aegypti and Cx. pipiens were examined for parasite DNA. B. malayi DNA was detected in voided materials of both species, but significantly more Cx. pipiens had detectible parasite DNA in their excreta and feces following a microfilaremic blood meal (Fig 3). Although external contamination could cause false positive PCR results, our mosquito co-housing results suggest that cross-contamination is probably uncommon.

However, to prevent cross-contamination, the following steps are recommended for processing wild-caught mosquitoes: (1) Immediately kill mosquitoes to limit mosquito-mosquito contact, especially if blood engorged mosquitoes are present; (2) When killing mosquitoes, avoid methods of slow death in which the mosquito host is killed and parasites are not, because it is possible for L3s to escape the body of living, dead, and dying mosquitoes, especially if mosquitoes come in contact with aqueous fluids [26-28]; (3) Pool mosquitoes as soon as possible after collection; (4) When sorting mosquitoes into pools, tools such as forceps and brushes should not pierce the mosquito body; and (5) Mosquito sampling should be restricted to whole females (head, thorax and abdomen intact). This will reduce error that could be introduced by testing random body parts from unidentified individuals.

Immunohistochemistry provides an alternative approach to detecting and studying parasite migration and development in mosquitoes; several studies have used this approach with antibodies to Plasmodium circumsporozoite protein (CSP) [16,29-31]. Most immunodiagnostic research on filariasis has focused on the parasite stages that occur within the vertebrate host [32,33], and this work has produced sensitive and specific diagnostic tests for Bancroftian and brugian filariasis $[5,34,35]$. In con- 


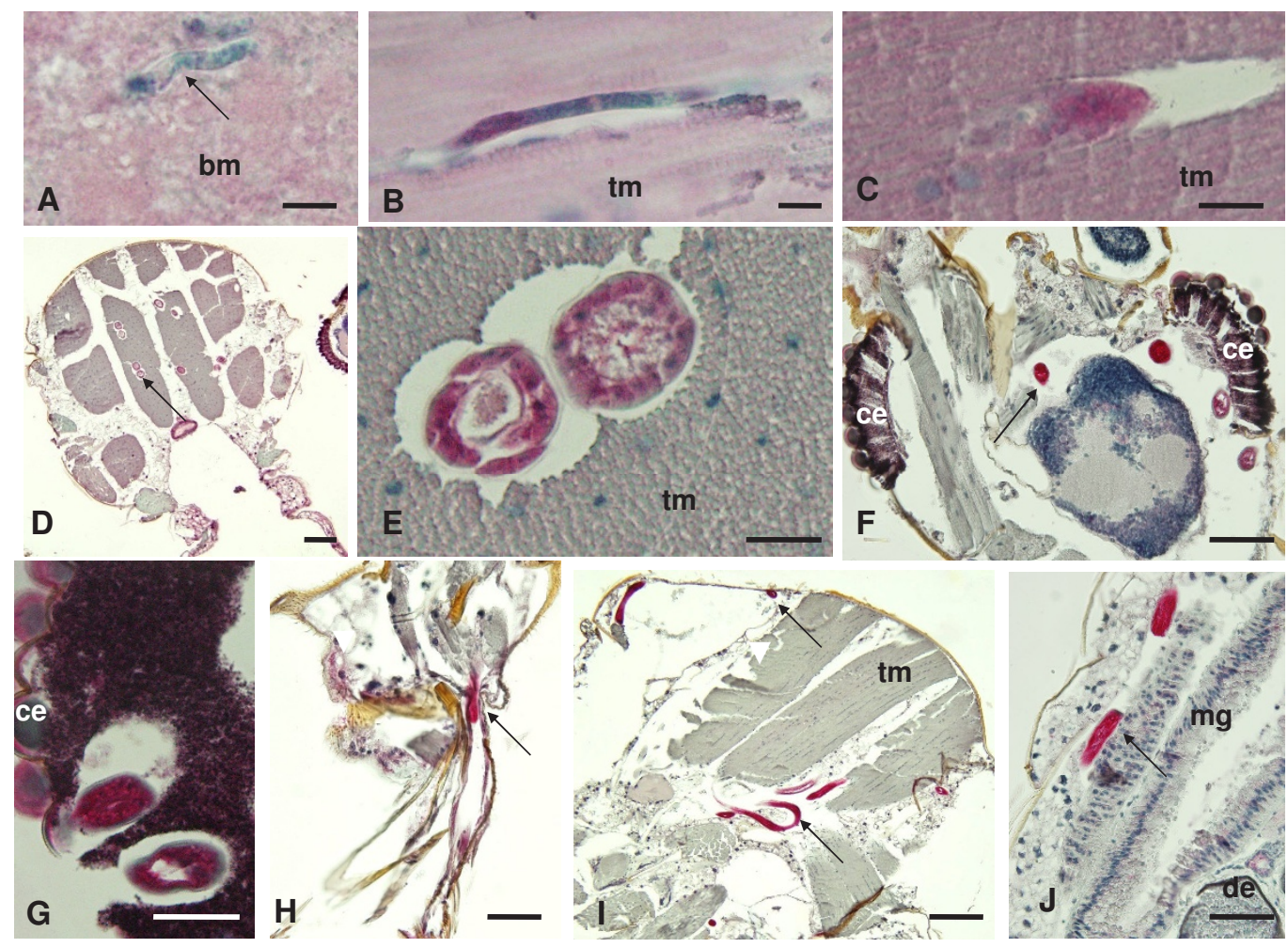

Figure 4

Immunohistological detection of B. malayi larvae in Ae. aegypti-LVP using polyclonal antibody to recombinant antigen Bm I 4. A Non-stained mf (arrow) in the midgut at I DPI: B Longitudinal section of a stained LI in the thorax muscles at I DPI: C Cross-section of a stained larva at 3 DPI: D Multiple cross-sections of strongly labeled L2s (arrow) at 7 DPI in the thorax. E Cross-sections of two strongly labeled L2s with body cavity and developing intestine at 7 DPI: F Overview of the head with 4 cross-sections of strongly labeled L3s (arrow) at I 4 DPI: G Cross-section of 2 well stained larvae close to the mosquito eye. $\mathbf{H}$ Labeled L3 at I4 DPI in the mosquito mouthparts. I Multiple strongly labeled L3s (arrows) in the thorax. J Strongly labeled L3 in the abdomen. (bm, blood meal; ce, compound eye; de, developing egg; tm, thorax muscles; mg, midgut; um, uterus membrane). Scale bars: A-C, E $25 \mu \mathrm{m}$; D, F-J $50 \mu \mathrm{m}$.

trast, few studies have examined antigen detection as a method for identifying and distinguishing LF parasites in mosquitoes. A monoclonal antibody raised against $B$. malayi $\mathrm{L} 3 \mathrm{~s}\left(\mathrm{NEB}-\mathrm{D}_{1} \mathrm{E}_{5}\right)$ is specific to a $B$. malayi $\mathrm{L} 3$ surface antigen and distinguishes $B$. malayi L3s from infectivestage larvae of other filarial worms apart from $B$. timori $[36,37]$. In the current study, antibodies to recombinant B. malayi antigen Bm14 [38,39] were used to detect this protein in filarial larvae in mosquitoes. Bm14 was detected in $\mathrm{mf}$ and all other developmental stages of parasites in the competent vector, Ae. aegypti-LVP. In contrast, the protein was not detected in parasites present in nonvector $C x$. pipiens (harboring $\mathrm{mf}$ in the midgut), or $A e$. aegypti-RKF (harboring parasites that developmentally arrest as L1s which then die within mosquito muscle cells). These results suggest that Bm14 may be a specific biomarker for viable filarial parasites in mosquitoes.

\section{Conclusion}

Improved methods are needed for assessing changes in mosquito infection and infectivity rates in the context of LF control/elimination programs. As infection rates in humans and vectors decrease following MDA, increased numbers of mosquitoes must be tested to accurately estimate parasite prevalence [40]. This makes dissection impractical, and favors use of molecular detection assays with pooled mosquitoes. This study provides new information on the persistence of filarial worm DNA in nonvectors that has practical implications for MX studies regarding methods for processing field-caught mosquitoes and for interpreting MX data. Additional studies are needed to determine whether the presence of Bm14 antigen is a reliable marker for viable filarial worms in pooled mosquito samples. Although this study focused on $B$. malayi, the findings may be of interest to scientists and 


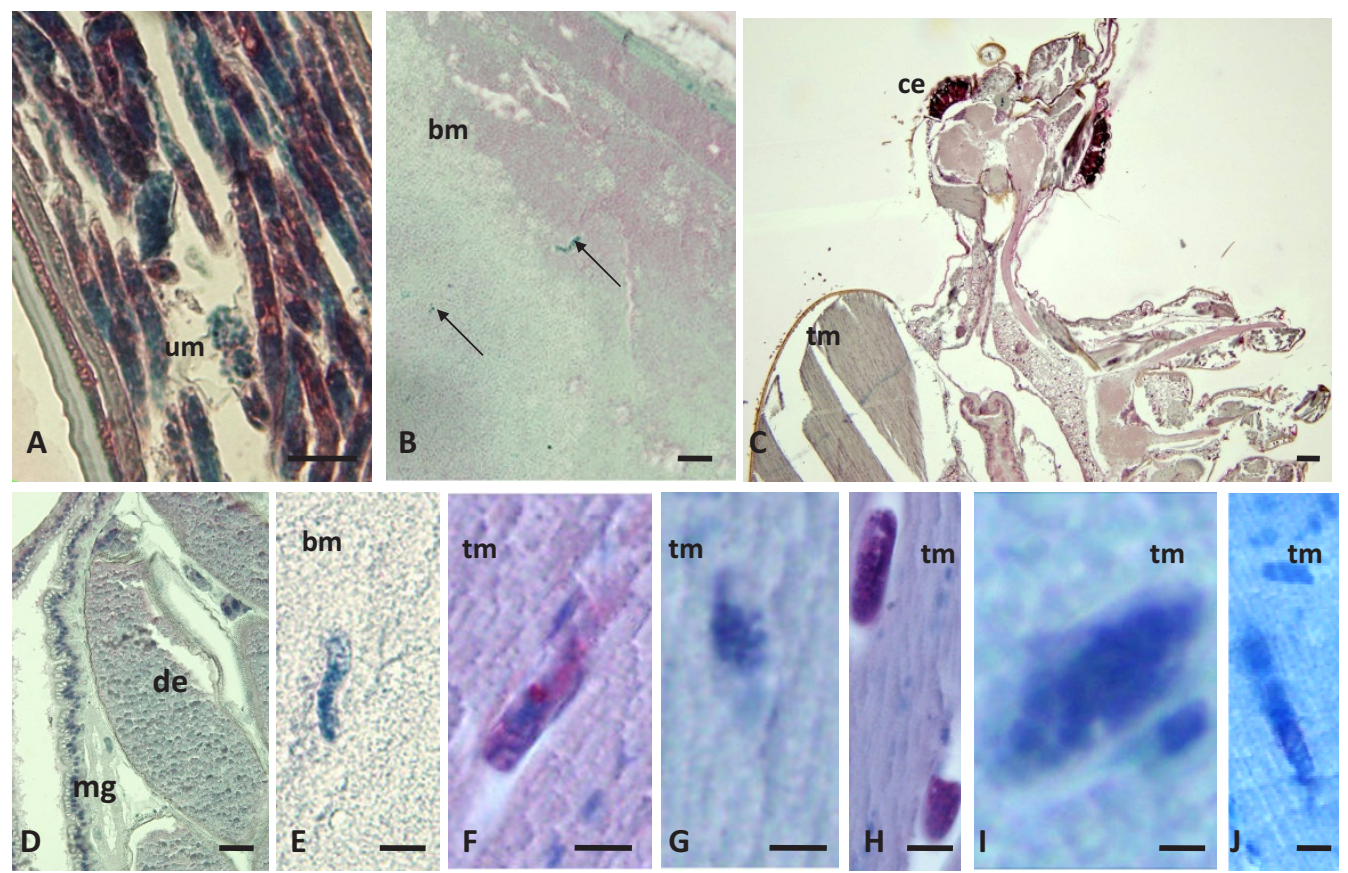

\section{Figure 5}

Immunohistological detection of B. malayi larvae in the uterus of adult B. malayi or in experimentally infected mosquitoes using polyclonal antibody to recombinant antigen Bm I 4. A The antibody labeled intra-uterine, stretched $\mathrm{mf}$ in an adult female B. malayi worm. B Multiple unlabeled mf in the midgut of $C x$. pipiens at $2 \mathrm{~h} \mathrm{Pl:} \mathrm{C} \mathrm{Overview} \mathrm{of} \mathrm{the} \mathrm{head} \mathrm{and}$ parts of the thorax at I4 DPI negative for B. malayi larvae. D Abdomen of Cx. pipiens at 3 DPI without any visible developing $B$. malayi larvae (labeled or unlabeled). E Magnified, unlabeled mf in the midgut of $C_{x}$. pipiens at $2 \mathrm{~h} \mathrm{PI:} \mathrm{F} \mathrm{Section} \mathrm{of} \mathrm{a} \mathrm{labeled} \mathrm{LI} \mathrm{in}$ the thorax muscles of Ae. aegypti-LVP at I DPI: G Section of an unlabeled LI in the thorax of Ae. aegypti-RKF at I DPI: H Two sections of labeled larvae in the thorax of Ae. aegypti-LVP at 3 DPI: I Section of an unlabeled larva in Ae. aegypti-RKF at 3 DPI. J Section of an unlabeled larva in Ae. aegypti-RKF at 7 DPI (compare Fig. 4D). Scale bars: A-D $25 \mu \mathrm{m}$; E-F I0 $\mu \mathrm{m}$.

programs that use molecular techniques to detect other pathogens (helminths, viruses, or protozoa) in vectors.

\section{Materials and methods}

\section{Mosquito maintenance and parasite exposures}

Mosquitoes used for these studies were obtained from colonies of Aedes aegypti (black-eyed, Liverpool strain; LVP), Ae. aegypti (Rockefeller strain; RKF) and Culex pipiens pipiens (Iowa strain) maintained at the University of Wisconsin-Madison, as previously described [21,41]. These mosquitoes differ in their vector competence for $B$. malayi. $A e$. aegypti-LVP support the development of $B$. malayi from $\mathrm{mf}$ to L3s, but parasites do not develop in $C x$. pipiens, because $\mathrm{mf}$ do not penetrate the midgut epithelium. In $A e$. aegypti-RKF, mf penetrate the mosquito midgut and migrate into thoracic muscles where they fail to develop to L2s. This mosquito strain was only used for comparison in the immunohistology experiments. Four- to seven-dayold mosquitoes were sucrose starved $\sim 14$ h prior to blood feeding. Mosquitoes were exposed to B. malayi by blood feeding on microfilaremic cat blood in a water-jacketed membrane feeder fitted with a parafilm membrane [42]. Mosquitoes also were blood fed on uninfected gerbils (Meriones unguiculatus) to serve as parasite-negative, blood-fed controls. Engorged mosquitoes were sorted and maintained in the laboratory.

Laboratory animals were handled according to guidelines approved by the Animal Care Committee at the University of Wisconsin-Madison. The $\mathrm{mf}$ densities of $B$. malayiinfected cat blood obtained from the NIAID Filariasis Research Reagent Repository Center http://www.filariasis center.org used in these studies ranged from 24-191 mf/ $20 \mu$ blood.

\section{Mosquito dissection}

Five mosquitoes were dissected at $2 \mathrm{hr}, 7 \mathrm{~d}$, and $14 \mathrm{~d}$ post ingestion of microfilaremic blood (PI) to estimate the mean intensity of infection, and to record the stage of $B$. malayi development. Individual mosquitoes were sepa- 
rated into head, thorax, midgut, and abdomen, and each body region was teased apart and individually examined for parasites by microscopy as previously described [10].

Ae. aegypti-LVP and Cx. pipiens were separated into body regions (head, thorax, midgut, and abdomen) and placed, separately or in pools of four, into $2.0 \mathrm{ml}$ microcentrifuge tubes for parasite DNA detection. To create a pooled sample, four mosquitoes were separated into body regions, and the body regions were combined by type into tubes. For example, four mosquitoes were used to produce one pool of four heads, one pool of four thoraces, one pool of four abdomens, and one pool of four midguts. Five pooled samples were prepared at $2 \mathrm{~h}, 1,3,7$, and $14 \mathrm{~d} \mathrm{PI}$; thus, a total of 20 mosquitoes were collected at each time point for pooled samples. In addition to creating pooled samples, individual mosquitoes were dissected into body regions as described above and then placed individually into tubes. Five individuals were dissected at each time point to create twenty samples: five tubes contained individual heads, five contained a single thorax, five contained an abdomen, and five contained a midgut. These samples were screened for $B$. malayi DNA to compare detection results between individuals and pooled samples. All samples were cataloged to track a given body region back to the particular mosquito or pool of mosquitoes, allowing the assay results from each body region to be combined into results for the 'whole mosquito.' For example, if at least one of the body region samples was positive; then the 'whole mosquito' was considered positive and only if all body regions tested negative; then the 'whole mosquito' was considered negative.

Collection of excreta and feces from individual mosquitoes To examine possible sources of parasite DNA contamination, mosquitoes were individually housed to collect material voided by excretion (excreta processed from Malphigian tubules) and defecation (feces containing undigested material from the midgut) [43]. Immediately following blood engorgement, mosquitoes were individually housed in $2.0 \mathrm{ml}$ microcentrifuge tubes. Mosquitoes were maintained for up to 4 DPI by providing $10 \%$ sucrose solution in drops on the mesh-screen top fitted on each tube. At $24 \mathrm{~h}$ intervals, mosquitoes and their voided matter were collected for DNA extraction. First, the mosquito was removed from the collection tube, transferred to a clean microcentrifuge tube and flash frozen in dry ice. Then, the collection tube containing the excreta and/or feces was labeled and also frozen. All samples were stored at $-80^{\circ} \mathrm{C}$ until DNA extraction. Five mosquitoes of each species were collected at $2 \mathrm{~h}$ and 1-4 d PI, and voided material was sampled at 1-4 DPI. In addition, the appearance of a blood bolus was recorded for each mosquito to provide data on the presence or absence of blood meal remnants within the mosquito midgut. Mosquitoes that blood fed on uninfected gerbils also were housed individually and sampled at each time point for negative controls.

\section{Co-housing studies to determine whether B. malayi DNA} is transferred from infected to uninfected mosquitoes Uninfected $A e$ aegypti were housed together with $B$. malayi-infected $C x$. pipiens that had fed on two B. malayiinfected gerbils with microfilaremias of 68 and $146 \mathrm{mf} / 20$ $\mu$ blood. Engorged Cx. pipiens were sorted from nonblood fed mosquitoes, and the engorged mosquitoes were mixed with non-blood fed Ae. aegypti. Four cartons were studied with each containing 60 uninfected Ae. aegypti and $\sim 40$ B. malayi-infected $C x$. pipiens. At 7 DPI, mosquitoes were collected for qPCR detection of parasite DNA. Cold anesthetized mosquitoes were sorted by species and placed in pools of five individuals for $C x$. pipiens and pools of ten individuals for Ae. aegypti. Mosquitoes were flash frozen on dry ice and stored at $-80^{\circ} \mathrm{C}$.

\section{DNA extraction and detection}

Genomic DNA from pooled mosquitoes or body parts was extracted using a commercial column method as described previously [10]. Quantitative real-time PCR was performed using an MGB probe to detect a 120 bp fragment of the Brugia HhaI repeat [44]. In all real-time PCR assays, water was used as no-template negative control; DNA extracted from a pool of non-infected mosquitoes acted as extraction negative control, and $100 \mathrm{pg}$ of DNA isolated from adult B. malayi was used as positive control.

\section{Immunohistology}

Five mosquitoes of each species were collected at 2 h, 1, 3, 7, and $14 \mathrm{~d}$ PI (i.e., the same time points as DNA detection assays) and stored in $80 \%$ ethanol at room temperature until embedding. Mosquitoes were embedded in paraffin, and $B$. malayi larvae were stained using the alkaline phosphatase anti-alkaline phosphatase method as described previously [45]. A polyclonal mouse antibody raised against recombinant $\mathrm{Bm} 14$ protein was used as the primary antibody for these studies [38].

\section{Statistical Analysis}

Data were graphed and analyzed with GraphPad Prism 5.0 http://www.graphpad.com. Fisher's exact tests, with two-tailed P-values, were used to compare parasite development and DNA detection between Ae. aegypti-LVP and $C x$. pipiens. Pearson correlation tests were used to test for trends in parasite DNA detection over time. Statistical results were considered significant at $P \leq 0.05$.

\section{List of abbreviations}

MF: microfilariae; L1, L2, L3: first- to third-stage larva; PI: post ingestion of microfilaremic blood; DPI: days post 
ingestion of microfilaremic blood; MX: molecular xenomonitoring.

\section{Competing interests}

The authors declare that they have no competing interests.

\section{Authors' contributions}

SE participated in the conception of the study including its design and organization, performed mosquito exposures and sample collection, data interpretation, statistical analysis, and drafted the manuscript. KF carried out the DNA detection and immunohistology assays, and data interpretation. GW participated in data interpretation and critical manuscript revisions. BC participated in study design, data interpretation, and critical manuscript revisions. PF participated in the conception of the study including its design and organization, data interpretation, and helped draft the manuscript. All authors read and approved the final manuscript.

\section{Acknowledgements}

We thank the NIAID/NIH Filariasis Research Reagent Repository Center (FR3) for supplying Brugia malayi -infected cat blood. This research was supported in part by the National Institutes of Health grants Al 0074I4-17 (graduate fellowship to SM Erickson), Al- 19769 (BM Christensen), Al065715 (GJ Weil), and by a Grant from The Barnes Jewish Hospital Foundation (GJ Weil).

\section{References}

I. WHO: Global programme to eliminate lymphatic filariasis. Wkly Epidemiol Rec 2007, 82:36I-380.

2. Michael E, Malecela MN, Zervos M, Kazura JW: Global eradication of lymphatic filariasis: the value of chronic disease control in parasite elimination programmes. PLOS ONE 2008, 3:e2936.

3. Kyelem D, Biswas G, Bockarie MJ, Bradley MH, El-Setouhy M, Fischer PU, Henderson RH, Kazura JW, Lammie PJ, Njenga SM, Ottesen EA, Ramaiah KD, Richards FO, Weil GJ, Williams SA: Determinants of success in national programs to eliminate lymphatic filariasis: a perspective identifying essential elements and research needs. Am J Trop Med Hyg 2008, 79:480-484.

4. Ramzy RM, El Setouhy M, Helmy H, Ahmed ES, Abd Elaziz KM, Farid HA, Shannon WD, Weil GJ: Effect of yearly mass drug administration with diethylcarbamazine and albendazole on bancroftian filariasis in Egypt: a comprehensive assessment. Lancet 2006, 367:992-999.

5. Weil G], Ramzy RM: Diagnostic tools for filariasis elimination programs. Trends Parasitol 2007, 23:78-82.

6. Bockarie MJ, Fischer P, Williams SA, Zimmerman PA, Griffin L, Alpers MP, Kazura JW: Application of a polymerase chain reactionELISA to detect Wuchereria bancrofti in pools of wild-caught Anopheles punctulatus in a filariasis control area in Papua New Guinea. Am J Trop Med Hyg 2000, 62:363-367.

7. Pedersen EM, Stolk WA, Laney SJ, Michael E: The role of monitoring mosquito infection in the Global Programme to Eliminate Lymphatic Filariasis. Trends Parasitol 2009, 25:31 9-327.

8. Hoti SL, Vasuki V, Lizotte MW, Patra KP, Ravi G, Vanamail P, Manonmani A, Sabesan S, Krishnamoorthy K, Williams SA: Detection of Brugia malayi in laboratory and wild-caught Mansonioides mosquitoes (Diptera: Culicidae) using Hha I PCR assay. Bull Entomol Res 200I, 91:87-92.

9. Fischer P, Wibowo H, Pischke S, Ruckert P, Liebau E, Ismid IS, Supali T: PCR-based detection and identification of the filarial parasite Brugia timori from Alor Island, Indonesia. Ann Trop Med Parasitol 2002, 96:809-82I.

10. Fischer P, Erickson SM, Fischer K, Fuchs JF, Rao RU, Christensen BM, Weil GJ: Persistence of Brugia malayi DNA in vector and non- vector mosquitoes: implications for xenomonitoring and transmission monitoring of lymphatic filariasis. Am J Trop Med Hyg 2007, 76:502-507.

II. Williams SA, Laney SJ, Bierwert LA, Saunders LJ, Boakye DA, Fischer P, Goodman D, Helmy H, Hoti SL, Vasuki V, Lammie PJ, Plichart C, Ramzy RM, Ottesen EA: Development and standardization of a rapid, PCR-based method for the detection of Wuchereria bancrofti in mosquitoes, for xenomonitoring the human prevalence of bancroftian filariasis. Ann Trop Med Parasitol 2002, 96(Suppl 2):S4I-46.

12. Farid HA, Morsy ZS, Helmy H, Ramzy RM, El Setouhy M, Weil GJ: A critical appraisal of molecular xenomonitoring as a tool for assessing progress toward elimination of Lymphatic Filariasis. Am J Trop Med Hyg 2007, 77:593-600.

13. Vasuki V, Hoti SL, Patra KP: RT-PCR assay for the detection of infective (L3) larvae of lymphatic filarial parasite, Wuchereria bancrofti, in vector mosquito Culex quinquefasciatus. J Vector Borne Dis 2008, 45:207-216.

14. Laney SJ, Buttaro CJ, Visconti S, Pilotte N, Ramzy RM, Weil GJ, Williams SA: A Reverse Transcriptase-PCR Assay for Detecting Filarial Infective Larvae in Mosquitoes. PLoS Negl Trop Dis 2008, 2:e25I.

15. Lombardi S, Esposito F, Zavala F, Lamizana L, Rossi P, Sabatinelli G, Nussenzweig RS, Coluzzi M: Detection and anatomical localization of Plasmodium falciparum circumsporozoite protein and sporozoites in the afrotropical malaria vector Anopheles gambiae s.I. Am J Trop Med Hyg 1987, 37:49I-494.

16. Beier MS, Schwartz IK, Beier JC, Perkins PV, Onyango F, Koros JK, Campbell GH, Andrysiak PM, Brandling-Bennett AD: Identification of malaria species by ELISA in sporozoite and oocyst infected Anopheles from western Kenya. Am J Trop Med Hyg 1988, 39:323-327.

17. da Rocha JA, de Oliveira SB, Povoa MM, Moreira LA, Krettli AU: Malaria vectors in areas of Plasmodium falciparum epidemic transmission in the Amazon region, Brazil. Am J Trop Med Hyg 2008, 78:872-877.

18. Yameogo L, Toe L, Hougard JM, Boatin BA, Unnasch TR: Pool screen polymerase chain reaction for estimating the prevalence of Onchocerca volvulus infection in Simulium damnosum sensu lato: results of a field trial in an area subject to successful vector control. Am J Trop Med Hyg 1999, 60: 124-I28.

19. Rodriguez-Perez MA, Katholi CR, Hassan HK, Unnasch TR: Largescale entomologic assessment of Onchocerca volvulus transmission by poolscreen PCR in Mexico. Am J Trop Med Hyg 2006, 74:1026-1033.

20. Paily KP, Hoti SL, Manonmani AM, Balaraman K: Longevity and migration of Wuchereria bancrofti infective larvae and their distribution pattern in relation to the resting and feeding behaviour of the vector mosquito, Culex quinquefasciatus. Ann Trop Med Parasitol 1995, 89:39-47.

21. Christensen BM, Sutherland DR: Brugia pahangi: Exsheathment and midgut penetration in Aedes aegypti. Transactions of the American Microscopical Society 1984, 103:423-433.

22. Obiamiwe BA: The fate of ingested Brugia pahangi microfilariae in susceptible and refractory strains of Culex pipiens and Aedes aegypti. Ann Trop Med Parasitol 1977, $71: 375-377$.

23. Omar MS, Zielke E: Abortive development of Wuchereria bancrofti in a West African strain of Culex pipiens fatigans. Tropenmed Parasitol 1978, 29:364-370.

24. Zielke $E$, Kuhlow $F$ : On the inheritance of susceptibility for infection with Wuchereria bancrofti in Culex pipiens fatigans. Tropenmed Parasitol 1977, 28:68-70.

25. Lowichik A, Lowrie RC Jr: Uptake and development of Wuchereria bancrofti in Aedes aegypti and Haitian Culex quinquefasciatus that were fed on a monkey with low-density microfilaremia. Trop Med Parasitol 1988, 39:227-229.

26. Gwadz RW, Chernin E: Escape of infective larvae of Brugia pahangi from Aedes aegypti into water. Trans $R$ Soc Trop Med Hyg 1973, 67:814-818.

27. Bosworth W, Sullivan JJ, Chernin E: Infective larvae of Brugia: escape from mosquitoes into water and subsequent oral infectivity in jirds. Am J Trop Med Hyg 1976, 25:700-703.

28. Zielke $E$ : On the escape of infective filarial larvae from the mosquitoes. Tropenmed Parasitol 1977, 28:46I-466.

29. Zavala F, Gwadz RW, Collins FH, Nussenzweig RS, Nussenzweig V: Monoclonal antibodies to circumsporozoite proteins identify 
the species of malaria parasite in infected mosquitoes. Nature 1982, 299:737-738.

30. Esposito F, Lombardi S, Toure YT, Zavala F, Coluzzi M: Field observations on the use of anti-sporozoite monoclonal antibodies for determination of infection rates in malaria vectors. Parassitologia 1986, 28:69-77.

31. Ryan JR, Dave K, Collins KM, Hochberg L, Sattabongkot J, Coleman RE, Dunton RF, Bangs MJ, Mbogo CM, Cooper RD, Schoeler GB, Rubio-Palis Y, Magris M, Romer LI, Padilla N, Quakyi IA, Bigoga J, Leke RG, Akinpelu O, Evans B, Walsey M, Patterson P, Wirtz RA, Chan AS: Extensive multiple test centre evaluation of the VecTest malaria antigen panel assay. Med Vet Entomol 2002, I 6:321-327.

32. Nanduri J, Kazura JW: Clinical and laboratory aspects of filariasis. Clin Microbiol Rev 1989, 2:39-50.

33. Harnett W, Bradley JE, Garate T: Molecular and immunodiagnosis of human filarial nematode infections. Parasitology 1998, I I 7(Suppl):S59-7I.

34. Weil GJ, Lammie PJ, Weiss N: The ICT Filariasis Test: A rapidformat antigen test for diagnosis of bancroftian filariasis. Parasitol Today 1997, I 3:401-404.

35. Jamail M, Andrew K, Junaidi D, Krishnan AK, Faizal M, Rahmah N: Field validation of sensitivity and specificity of rapid test for detection of Brugia malayi infection. Trop Med Int Health 2005, 10:99-104.

36. Carlow CK, Franke ED, Lowrie RC Jr, Partono F, Philipp M: Monoclonal antibody to a unique surface epitope of the human filaria Brugia malayi identifies infective larvae in mosquito vectors. Proc Natl Acad Sci USA 1987, 84:6914-69l8.

37. Carlow CK, Perrone J, Spielman A, Philipp M: A developmentally regulated surface epitope expressed by the infective larva of Brugia malayi which is rapidly lost after infection. In Molecular paradigms for eradicating helminthic parasites Edited by: Maclnnis AJ. New York: Alan R. Liss, Inc; 1987:301-310.

38. Chandrashekar R, Curtis KC, Ramzy RM, Liftis F, Li BW, Weil G]: Molecular cloning of Brugia malayi antigens for diagnosis of lymphatic filariasis. Mol Biochem Parasitol 1994, 64:26 I-27I.

39. Lammie PJ, Weil G, Noordin R, Kaliraj P, Steel C, Goodman D, Lakshmikanthan VB, Ottesen E: Recombinant antigen-based antibody assays for the diagnosis and surveillance of lymphatic filariasis - a multicenter trial. Filaria J 2004, 3:9.

40. Katholi CR, Unnasch TR: Important experimental parameters for determining infection rates in arthropod vectors using pool screening approaches. Am J Trop Med Hyg 2006, 74:779-785.

4I. Bartholomay LC, Farid HA, Ramzy RM, Christensen BM: Culex pipiens pipiens: characterization of immune peptides and the influence of immune activation on development of Wuchereria bancrofti. Mol Biochem Parasitol 2003, 130:43-50.

42. Rutledge LC, Ward RA, Gould DJ: Studies on the feeding response of mosquitoes to nutritive solutions in a new membrane feeder. Mosquito News 1964, 24:407-419.

43. Clements AN: The biology of mosquitoes Ist edition. New York: Chapman \& Hall; 1992.

44. Rao RU, Weil G], Fischer K, Supali T, Fischer P: Detection of Brugia parasite DNA in human blood by real-time PCR. J Clin Microbiol 2006, 44:3887-3893.

45. Rao RU, Huang Y, Fischer K, Fischer PU, Weil G]: Brugia malayi: Effects of nitazoxanide and tizoxanide on adult worms and microfilariae of filarial nematodes. Exp Parasitol 2009, | 2 |:38-45
Publish with Biomed Central and every scientist can read your work free of charge

"BioMed Central will be the most significant development for disseminating the results of biomedical research in our lifetime. "

Sir Paul Nurse, Cancer Research UK

Your research papers will be:

- available free of charge to the entire biomedical community

- peer reviewed and published immediately upon acceptance

- cited in PubMed and archived on PubMed Central

- yours - you keep the copyright

Submit your manuscript here:

http://www.biomedcentral.com/info/publishing_adv.asp
BioMedcentral 